\title{
DIAGNÓSTICO DO USO E COBERTURA DO SOLO EM ÁREAS DE PRESERVAÇÃO PERMANENTE E A QUALIDADE DA ÁGUA DE DOIS RIOS NA BACIA DO ALTO PARANAPANEMA
}

\section{Bruna Renata de Melo Dino ${ }^{1}$ André Marcondes Andrade Toledo²}

\author{
'Bacharel em Engenharia Ambiental da Universidade Federal de São Carlos (UFSCar), Buri- \\ SP, Brasil. \\ E-mail: brunadino@estudante.ufscar.br \\ 2Professor Doutor do curso de Engenharia Ambiental da UFSCar, Buri-SP, Brasil.
}

\section{Recebido em: 15/08/2020 - Aprovado em: 15/09/2020 - Publicado em: 30/09/2020 DOI: 10.18677/EnciBio_2020C15}

\begin{abstract}
RESUMO
Os recursos hídricos sofrem inúmeros impactos devido as ações antrópicas e por isso podem ser indicadores de alterações do uso e ocupação do solo em bacias hidrográficas. Objetivou-se neste trabalho avaliar o uso e ocupação do solo nas subbacias do rio Paranapanema e Itapetininga, na região sudoeste do estado de São Paulo, e a qualidade da água superficial na área de confluência desses rios. Neste contexto, realizou-se a caracterização e diagnóstico do uso e ocupação do solo nas áreas de preservação permanente (APPs), por meio do geoprocessamento, utilizando imagens de satélites e os softwares ArcMap 10.6.1, ArcGIS Pro e Google Earth Pro. As análises de qualidade da água foram realizadas em quatro pontos, com sonda multiparâmetro, considerando os seguintes parâmetros: temperatura, $\mathrm{pH}$, oxigênio dissolvido, turbidez, sólidos totais dissolvidos e condutividade elétrica. A partir dos resultados gerados foi possível verificar que a sub-bacia do rio ltapetininga sofreu maiores impactos antrópicos, uma vez que as APPs se apresentam mais degradadas e os parâmetros turbidez, sólidos totais dissolvidos e condutividade elétrica mais elevados quando comparados ao rio Paranapanema.
\end{abstract}

PALAVRAS-CHAVE: Áreas de preservação permanente, bacia hidrográfica, geoprocessamento.

\section{USE AND COVERAGE DIAGNOSIS OF THE SOIL IN PERMANENT PRESERVATION AREAS AND WATER QUALITY OF TWO RIVERS IN ALTO PARANAPANEMA WATERSHED}

\begin{abstract}
Water resources suffer numerous impacts due to anthropic actions and, therefore, they can be indicators of changes in land use and occupation in watersheds. The objective of this work was to evaluate the use and occupation of the soil in the subbasins of the Paranapanema and Itapetininga River, in the southwest region of the state of São Paulo, and the quality of surface water in the confluence area of these rivers. In this context, the characterization and diagnosis of land use and occupation in permanent preservation areas (PPAs) was carried out, through geoprocessing, using satellite images and the softwares ArcMap 10.6.1, ArcGIS Pro and Google Earth Pro. The water quality was analyzed in four points, with a multiparameter probe, considering the following parameters: temperature, $\mathrm{pH}$, dissolved oxygen, turbidity, total dissolved solids and electrical conductivity. From the results, it was
\end{abstract}


possible to verify that the Itapetininga River sub-basin suffered greater anthropic impacts, once APPs are more degraded and the parameters turbidity, total dissolved solids and electrical conductivity higher when compared to the Paranapanema River.

KEYWORDS: Permanente preservation areas, watersheds, geoprocessing.

\section{INTRODUÇÃO}

A água é essencial para a vida de todos os seres vivos e fundamental para muitas das atividades humanas, fortalecendo o desenvolvimento econômico e social de uma sociedade. Ademais, é um ótimo indicador dos efeitos das ações antrópicas nos ecossistemas, uma vez que está vinculada a uma série de processos da natureza (SILVA et al., 2017).

De acordo com a Agência Nacional de Águas (ANA, 2019), no Brasil cerca de $66,1 \%$ da água consumida é destinada para irrigação de atividades agrícolas. Além do alto consumo de água, a produção agrícola em larga escala faz uso de agrotóxicos e fertilizantes, os quais geralmente impactam negativamente ecossistemas e comprometem a qualidade da água dos sistemas fluviais (GOMES, 2019).

Historicamente, a fim de obter mais espaço para atividades humanas, observam-se extensas áreas agrícolas próximas aos cursos d'água, isto é, em áreas de preservação permanente (APPs) (REZENDE;ARAÚJO, 2016), as quais são protegidas pelo Código Florestal Brasileiro, Lei no 12.651/2012 (BRASIL, 2020a).

Neste contexto, vale ressaltar que o estado de São Paulo possuía originalmente cerca de $80 \%$ de sua área coberta por floresta. Com o avanço da agricultura e urbanização, que resultou na ocupação do interior paulista nos últimos 150 anos, atualmente apenas 7\% desta área continua recoberta com vegetação nativa (BRASIL, 2010). A partir de dados obtidos do MapBiomas (2019), um projeto de mapeamento anual da cobertura e uso do solo do Brasil, o qual contribui para a compreensão da dinâmica do uso do solo, observou-se que em 2016 aproximadamente $70 \%$ do solo do estado de São Paulo era utilizado para agropecuária (pastagem e agricultura). A região Sul do estado é a que apresenta a maior área com remanescente da mata atlântica, onde está inserida a bacia do Alto Paranapanema, com alto potencial hídrico, mas mesmo assim apenas $20 \%$ da sua área é coberta por vegetação nativa (SÃO PAULO, 2018).

Com a redução da vegetação, matas ciliares e o uso incorreto do solo, a interação da água com o solo é modificada e consequentemente a infiltração natural, o destino final e sua qualidade, por exemplo, também são alterados (SILVA et al., 2017). A gestão dos recursos hídricos brasileiros é baseada na Lei 9.433/97 conhecida como "Lei das águas" (BRASIL, 2020b), na qual aborda (Art. 3ํ) a relação da gestão de recursos hídricos com a do uso do solo e a gestão ambiental, e considera que a implementação da Política Nacional de Recursos Hídricos deve ocorrer nas bacias hidrográficas.

As bacias hidrográficas são importantes para estudos ambientais, auxiliando na identificação, mensuração, diagnósticos e gestão dos recursos naturais devido a interação entre os aspectos físicos e os tipos de uso e ocupação do solo (SILVA et al., 2017). Pode-se segmentar bacias hidrográficas em sub-bacias de acordo com a necessidade e interesse do estudo. A caracterização dos aspectos físicos, bióticos e antrópicos de bacias hidrográficas é possível por meio do geoprocessamento, o qual dispõe de conjunto de ferramentas utilizadas para coleta, tratamento e geração de dados georreferenciados. Neste contexto, considera-se a possibilidade de obtenção de dados da superfície da Terra, por meio de produtos oriundos do sensoriamento remoto, destacando as imagens aéreas ou orbitais (GUEDES; SILVA, 2018). 
De acordo com Guedes e Silva (2018) é possível detectar e medir quantitativa e qualitativamente o resultado da interação entre a radiação eletromagnética em diferentes objetos terrestres. Portanto é um processo fundamental para mapeamento e monitoramento de recursos naturais. Estes instrumentos têm sido muito utilizados em avaliações ambientais, como para estudos voltados às bacias hidrográficas que possuem influência muito ampla em âmbitos econômicos, sociais e institucionais.

Diante disso, observa-se que é de suma importância desenvolver pesquisas que visam analisar, com auxílio da técnica de geoprocessamento, a relação do uso e cobertura do solo e a qualidade da água de rios, bem como o diagnóstico em áreas de preservação permanente (APPs), para auxiliar no entendimento da dinâmica territorial relacionada à influência antrópica em bacias hidrográficas. Neste sentido, este estudo teve como objetivo caracterizar o uso e cobertura do solo em áreas de preservação permanente e analisar a relação destes com a qualidade da água superficial dos rios Itapetininga e Paranapanema, com o auxílio da técnica de geoprocessamento e sonda multiparâmetro.

\section{Localização e caracterização da área de estudo \\ MATERIAL E MÉTODOS}

Considerou-se nesta pesquisa as sub-bacias do rio Itapetininga e rio Paranapanema, inseridas na Bacia Hidrográfica do Alto Paranapanema. Juntas abrangem uma área de 5.873,37 $\mathrm{km}^{2}$ na região Sudoeste do estado de São Paulo e envolvem os municípios de Campina do Monte Alegre, Buri, Itapetininga, Angatuba, Ribeirão Grande, Capão Bonito, São Miguel Arcanjo, Sarapuí, Pilar do Sul, Piedade e Tapiraí, como representado na Figura 1 (A). Os municípios de Itapetininga e Capão Bonito são os mais populosos, com 162.231 e 46.428 habitantes, respectivamente. O clima da região é tropical úmido, com elevadas temperaturas e alto teor de umidade (SIGRH, 2019a). Na região sob estudo ocorrem intensas atividades agroindustriais (SIGRH, 2019b).

FIGURA 1- Área de estudo, municípios inseridos e delimitação das sub-bacias: Itapetininga (em amarelo) e Paranapanema Superior (em vermelho).
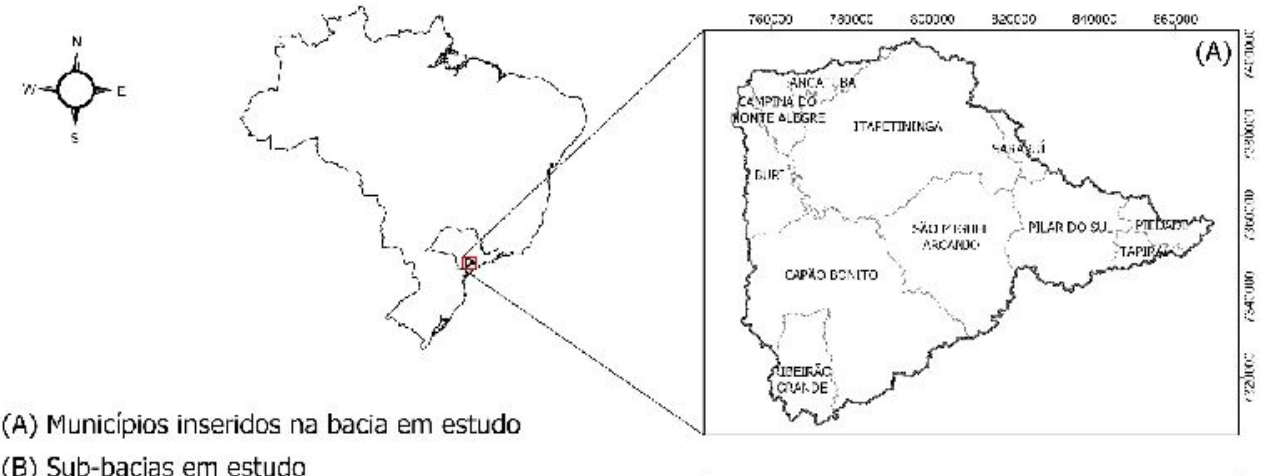

(B) Sub-bacias em estudo
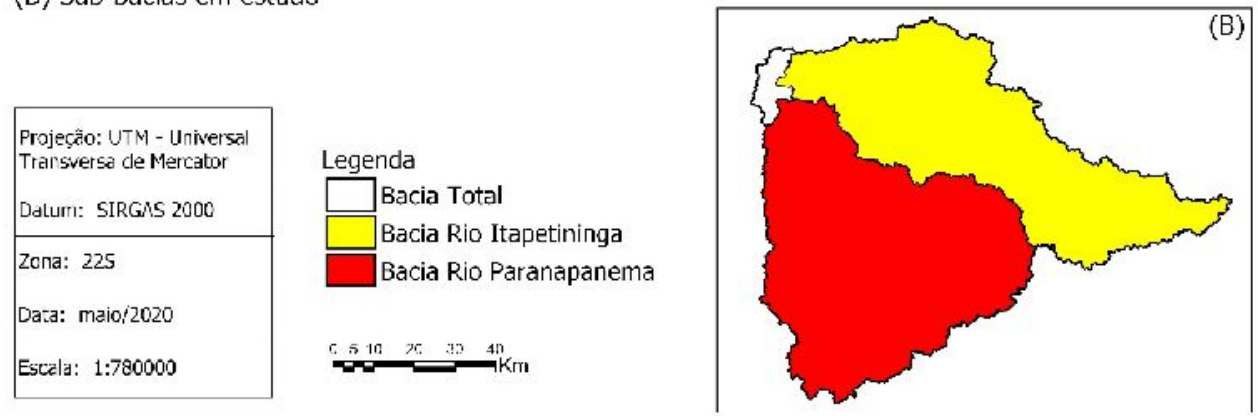

Fonte: Autores (2020) 
A sub-bacia do rio Itapetininga possui formato alongado, $116 \mathrm{~km}$ de extensão noroeste-sudeste e $40 \mathrm{~km}$ nordeste-sudoeste, aproximadamente. Sua área é de $2.610,492 \mathrm{~km}^{2}$ e engloba oito dos doze municípios citados acima. A sub-bacia do Paranapanema Superior possui área de $3.149,748 \mathrm{~km}^{2}$. O trecho superior do Paranapanema é de aproximadamente $73 \mathrm{~km}$ noroeste-sudeste e $50 \mathrm{~km}$ nordestesudoeste. Ambas sub-bacias estão representadas na Figura 1 (B).

\section{Período de estudo}

O estudo foi realizado durante 12 meses, de agosto de 2018 a agosto de 2019, a fim de compreender as estações secas e chuvosas do ano. As análises de água foram feitas nos meses de outubro e dezembro de 2018 e abril e agosto de 2019.

\section{Aquisição e processamento de dados}

Mapas bases como a hidrografia e limites municipais foram obtidos a partir da plataforma DataGEO - sistema ambiental paulista, da Secretaria de Infraestrutura e Meio Ambiente do estado de São Paulo. As imagens SRTM (Shuttle Radar Topography Mission) e do satélite Landsat 8 , com resolução espacial de 30 metros, foram adquiridos da plataforma do USGS (United States Geological Survey), sendo as imagens Landsat correspondentes a data de 02/04/2019, cenas 220076 e 220077.

A projeção de todos os dados foi unificada em UTM (Universal Transversa de Mercator, zona 22S) e Datum SIRGAS 2000 (Sistema de Referência Geocêntrico para as Américas). Essa projeção do tipo elipsoide é adotada como sistema de referência geodésico para o Sistema Geodésico Brasileiro (SGB), segundo o Instituto Brasileiro de Geografia e Estatística (IBGE, 2005).

\section{Delimitação da bacia total e sub-bacias (método SRTM)}

O processamento dos dados e caracterização dos aspectos físicos e de uso e ocupação do solo foram realizados por meio de ferramentas disponíveis no programa ArcMap 10.6.1. As sub-bacias foram delimitadas por meio do processamento de imagem SRTM, que representa um modelo digital de elevação (MDE) da superfície terrestre (NASA, 2002). Neste sentido, inicialmente gerou-se a hidrografia, utilizando o módulo ArcToolbox, no qual constam ferramentas de análise espacial (Spatial Analyst Tools), selecionando a opção Hydrology. Com a rede de drenagem elaborada, criou-se pontos (exutórios) no curso principal, dois no rio Paranapanema um antes e um após a confluência com o rio Itapetininga, e outro no trecho final do curso d'água do rio Itapetininga. A partir desses pontos foram delimitadas as áreas das sub-bacias.

\section{Composição colorida e fusão de imagem}

Com as bandas seis, cinco e quatro, correspondentes aos comprimentos de onda do infravermelho médio, infravermelho próximo e vermelho, respectivamente, do Landsat 8, foi elaborada a composição colorida, por meio da ferramenta Composite Bands do ArcMap. A fim de melhorar a resolução espacial da imagem gerada - composição colorida, realizou-se o processo de fusão de imagem - Create Pan-sharpened Raster Dataset, considerando a imagem pancromática do Landsat 8, gerando como produto final uma imagem com resolução espacial de 15 metros.

\section{Mapa de uso do solo}

$\mathrm{Na}$ imagem resultante, composição de bandas, foram identificadas e delimitadas amostras de classes de uso e ocupação do solo consideradas nesta 
pesquisa, sendo: 'água', 'floresta' e 'não floresta'. A partir dessas amostras realizouse a classificação supervisionada, pelo algoritmo de máxima verossimilhança, obtendo como produto uma imagem na qual cada pixel corresponde a uma das três classes mencionadas.

\section{Delimitação da área de preservação permanente (APP)}

Após proceder a sobreposição da rede de drenagem e a imagem composição colorida, e constatar algumas incoerências no traçado dos rios, foi necessário ajustar visualmente, corrigindo com auxílio da barra de comando de edição vetorial - editor.

Com o auxílio da plataforma Google Earth Pro, mediu-se a largura dos rios sendo possível constatar que ambos possuem largura entre 10 e 50 metros. Sendo assim, de acordo com o Código Florestal, as áreas de preservação permanente de ambos correspondem a 50 metros. Considerou-se a largura média de 40 metros para os rios e, por fim, determinou-se um buffer de 70 metros para cada lado da linha que representa o canal principal do rio, sendo 20 metros referente a metade da largura do rio e 50 metros a faixa de APP de cada margem do rio, totalizando 140 metros de buffer.

\section{Análise da água}

Para analisar os parâmetros da água determinaram-se quatro pontos na área de estudo, sendo um ponto em cada rio, antes do ponto de confluência destes, um ponto após a confluência e um ponto após a estação de tratamento de esgoto da cidade de Campina do Monte Alegre, conforme apresentados na Tabela 1.

QUADRO 1- Informações geográficas dos pontos de análise de água.

\begin{tabular}{|c|c|c|c|}
\hline Ponto & Localização & Latitude & Longitude \\
\hline 1 & Rio Paranapanema & $23^{\circ} 38^{\prime} 20.15^{\prime \prime S}$ & $48^{\circ} 28^{\prime} 20.64^{\prime \prime O}$ \\
\hline 2 & Rio Itapetininga & $23^{\circ} 36^{\prime} 8.35^{\prime \prime S}$ & $48^{\circ} 27^{\prime} 1.81^{\prime \prime O}$ \\
\hline 3 & $\begin{array}{l}\text { Rio Paranapanema após confluência com } \\
\text { Itapetininga }\end{array}$ & $23^{\circ} 36^{\prime} 36.51 " \mathrm{~S}$ & $48^{\circ} 29^{\prime} 6.26 " \mathrm{O}$ \\
\hline 4 & $\begin{array}{c}\text { Rio Paranapanema após estação de } \\
\text { tratamento de esgoto de Campina do Monte } \\
\text { Alegre }\end{array}$ & $23^{\circ} 35^{\prime} 30.38 " S$ & $48^{\circ} 29^{\prime} 34.25^{\prime \prime O}$ \\
\hline
\end{tabular}

Fonte: Autores (2020)

O ponto um representa a área de drenagem a montante do rio Paranapanema, assim como o ponto dois aquela a montante do rio Itapetininga. $O$ ponto três representa a qualidade da água após a junção dos dois rios e o ponto quatro possível alteração na qualidade da água em decorrência da estação de tratamento de esgoto (ETE) da cidade de Campina do Monte Alegre, a qual está situada próximo à margem do rio, entre os pontos três e quatro. A Figura 2 apresenta a região das análises e os respectivos pontos. 
FIGURA 2- Pontos de análises de água.

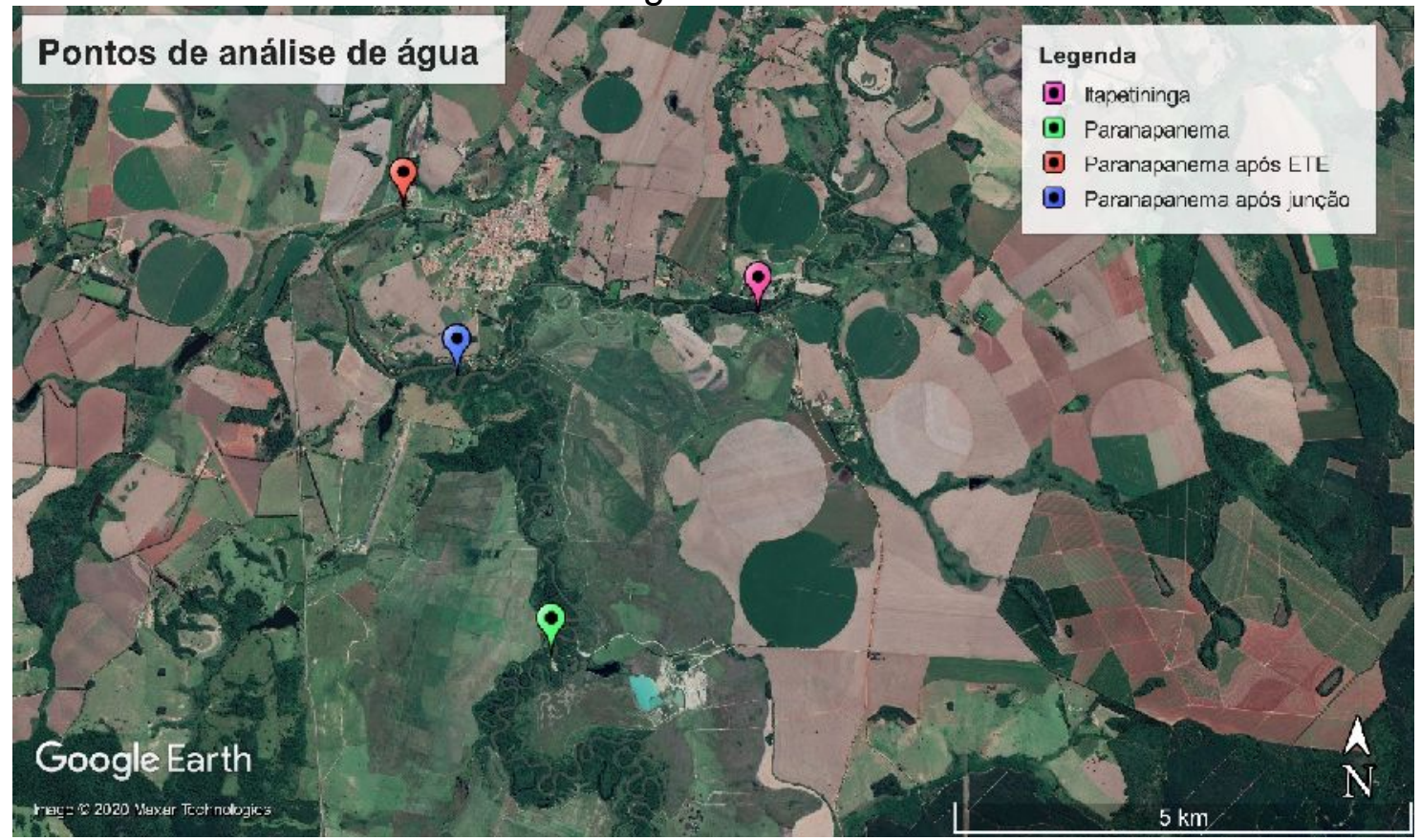

Fonte: Adaptado de Google Earth

Para medição dos parâmetros utilizou-se uma sonda multiparâmetro - HANNA HI 9829 Multiparameter - previamente calibrada - e um GPS Garmin etrex 10 para determinar as coordenadas dos pontos de análise (Figura 3). A Tabela 2 apresenta os parâmetros analisados e discutidos na presente pesquisa.

FIGURA 3- Sonda HANNA Multiparameter e GPS Garmin.

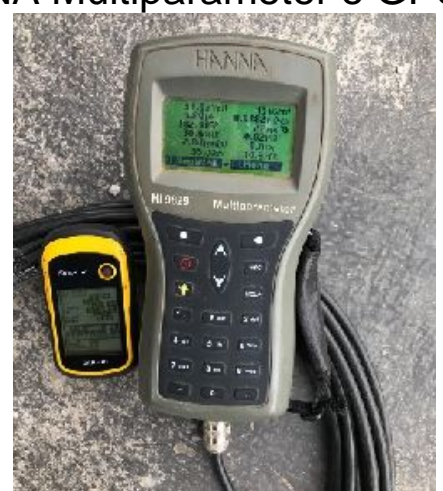

Fonte: Autores (2020)

QUADRO 2- Parâmetros analisados.

\begin{tabular}{ll} 
Potencial Hidrogeniônico $(\mathrm{pH})$ & $\mathrm{pH}$ \\
\hline Oxigênio Dissolvido (OD) & $\mathrm{mg} / \mathrm{L}$ \\
\hline Temperatura & $\stackrel{\circ}{ } \mathrm{F}$ \\
\hline Turbidez & $\mathrm{FNU}$ \\
\hline Sólidos Totais Dissolvidos & $\mathrm{ppm}$ \\
\hline Condutividade Elétrica & $\mathrm{S} / \mathrm{cm}$
\end{tabular}

Fonte: Autores (2020)

Para o mês de outubro de 2018 os parâmetros de sólidos totais dissolvidos, turbidez e pH foram analisados em laboratório para verificar se a sonda estava 
funcionando corretamente. Na terceira coleta, em abril, utilizou-se outra sonda específica para oxigênio dissolvido, a fim de verificar este parâmetro. Posteriormente, os valores obtidos em todas as coletas foram computados e comparados com a Resolução CONAMA no 357, de 17 de março de 2005 (CONAMA, 2005).

\section{RESULTADOS E DISCUSSÃO}

A Figura 4 apresenta a hidrografia das sub-bacias, obtida a partir da imagem SRTM, e a localização dos pontos de análise da água.

FIGURA 4- Hidrografia das sub-bacias, Itapetininga e Paranapanema, e localização dos pontos de análise.

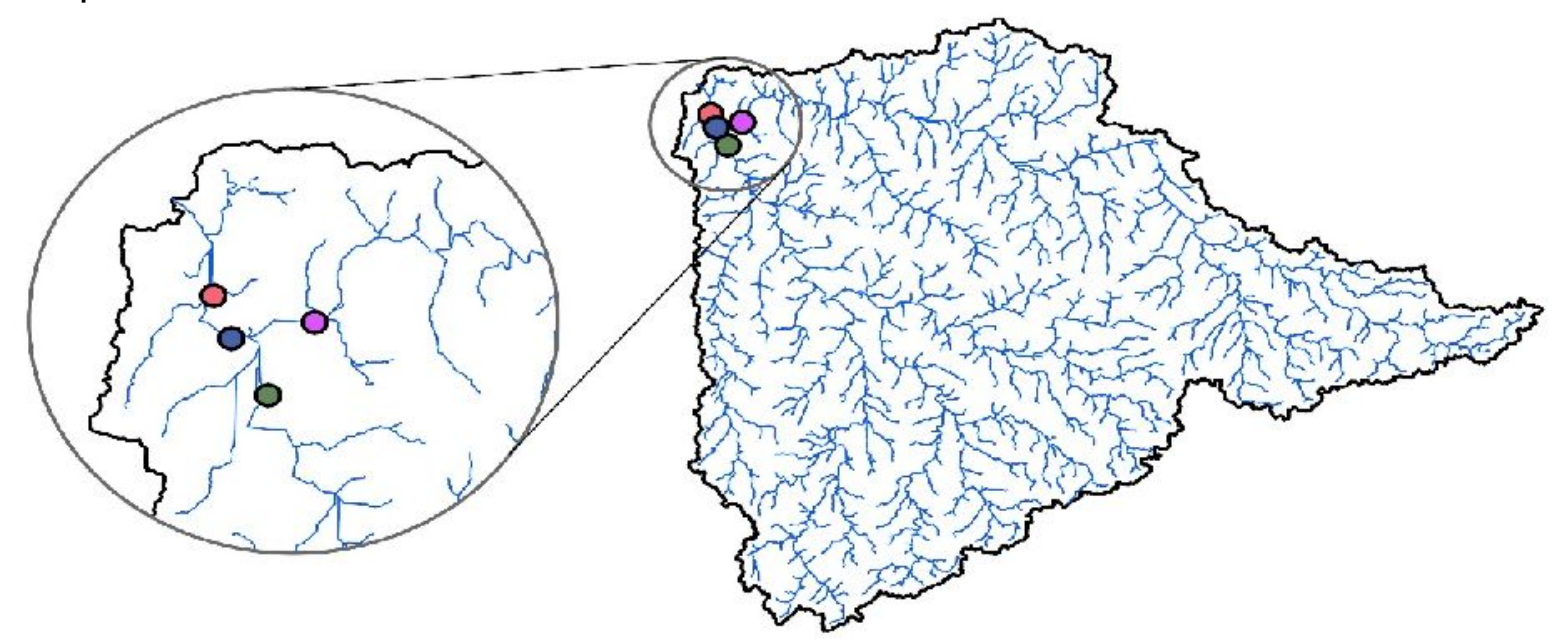

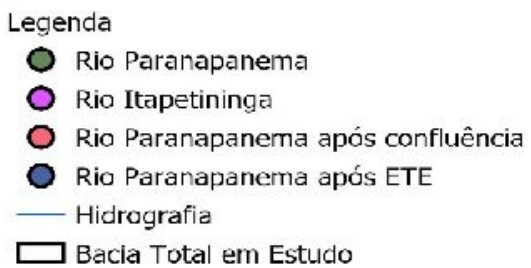

Fonte: Autores (2020)

A partir da imagem de composição colorida realizou-se a classificação supervisionada obtendo o mapa de uso do solo (Figura 5), com as três classes estabelecidas - água, floresta e não floresta, o qual foi utilizado posteriormente para realizar a análise nas áreas de preservação permanente.

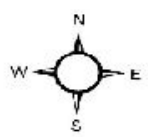


FIGURA 5- Mapa de classificação do uso do solo da bacia total

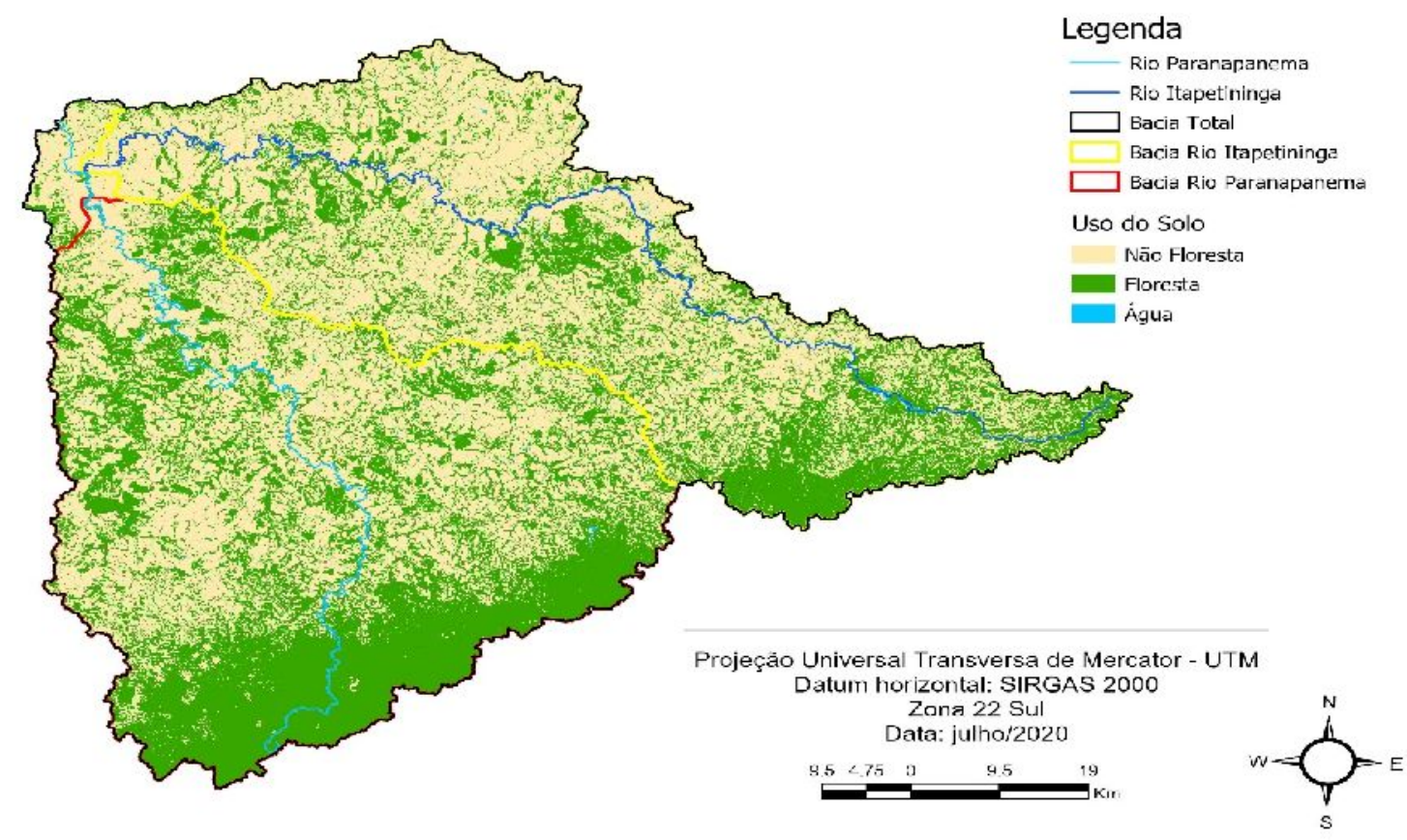

Fonte: Autores (2020)

O Plano de Bacia do Alto Paranapanema (CBH-ALPA, 2016) aborda 13 categorias de uso do solo encontrados na bacia e aponta que a vegetação nativa representa quase $25 \%$ da área da bacia, isto porque contempla áreas protegidas por lei como parques estaduais. Ao longo da bacia, nas áreas caracterizadas por "Não Floresta" verifica-se extensas áreas com predominância de atividades agropecuárias. Conforme pode ser observado na Figura 5, os remanescentes da vegetação nativa estão fragmentados (CBH-ALPA, 2016) e mais concentrados na porção sul e sudeste, onde encontram-se parques estaduais de proteção integral, como o Parque Estadual Carlos Botelho e o Parque Estadual Intervales. Nesse último está situada a nascente do rio Paranapanema.

Como resultado do processamento de sobreposição da APP com o mapa de uso e ocupação do solo foi possível verificar que na área de preservação do rio Itapetininga encontram-se $55,65 \%$ de vegetação nativa (floresta) e $44,35 \%$ com outras formas de uso, caracterizando, neste caso, passivo ambiental, ou seja, área de preservação permanente degradada (APPD). Já o rio Paranapanema possui $71,91 \%$ de área preservada e $28,09 \%$ de outros usos. Em termos de área, as APPDs ocorrem em $4,20 \mathrm{~km}^{2}$ nas margens do rio Paranapanema, enquanto no rio Itapetininga em $8,37 \mathrm{~km}^{2}$.

A ausência de mata ciliar favorece o carreamento de sedimentos para o curso d'água, levando produtos químicos e matéria orgânica. Neste contexto, salienta-se a importância de manutenção da vegetação nativa, em especial a mata ciliar, que auxilia na infiltração da água, retenção de partículas e, consequentemente, preservação do solo. Além de contribuir com umidade, também desacelera o processo de escoamento superficial. Portanto, regiões com alto índice de degradação da vegetação nativa afetam a qualidade da água (AMÉRICO-PINHEIRO et al., 2016).

Quanto às análises de qualidade da água, realizaram-se quatro visitas a campo nos meses de outubro e dezembro de 2018 e abril e agosto de 2019 abrangendo todas as estações do ano. Nessa região ocorre maior intensidade de chuva nos 
meses com temperaturas mais elevadas (novembro a março) e os meses mais frios (maio a agosto) são mais secos. Sendo assim, com a redução da vazão do rio no inverno diminui-se também a erosão hídrica e, com isso, um menor transporte de sedimentos para o rio. Na Figura 6 pode-se observar a variação dos parâmetros temperatura, $\mathrm{pH}$, oxigênio dissolvido, turbidez, sólidos totais dissolvidos $\mathrm{e}$ condutividade elétrica, analisados para os quatro pontos nos quatro períodos.

FIGURA 6 - Distribuição dos valores dos parâmetros analisados: (a) Temperatura oC, (b) pH, (c) Oxigênio Dissolvido (OD) mg/L, (d) Turbidez FNU, (e) Sólidos Totais Dissolvidos ppm tds, (f) Condutividade Elétrica $\mathrm{S} / \mathrm{cm}$. O ponto 1 - encontra-se jusante do Rio Paranapanema; ponto 2 - a jusante do Rio Itapetininga; ponto 3 - a confluência dos Rios Itapetininga e Paranapanema e o ponto 4 - localizado após a estação de tratamento de esgoto de Campina do Monte Alegre.

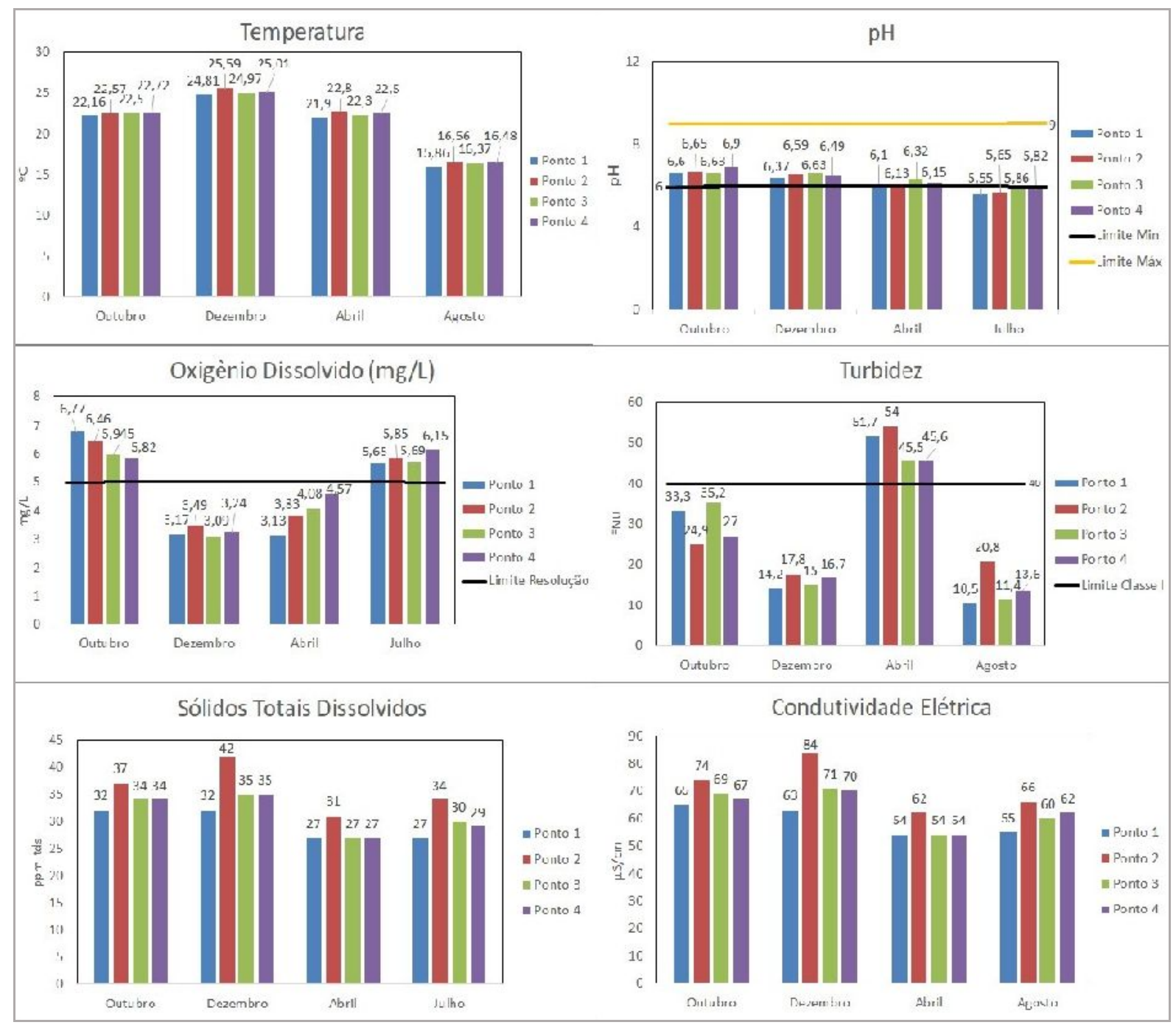

Fonte: Autores (2020)

Diversos processos físicos, químicos e biológicos que ocorrem na água são influenciados pela temperatura. Quando ocorre a elevação da temperatura, por exemplo, a solubilidade de gases diminui e aumenta a reação dos processos de Demanda Bioquímica de Oxigênio (DBO) (AMARAL et al., 2019). Durante as análises verificou-se que a temperatura variou em cerca de $2,5^{\circ} \mathrm{C}$ de uma estação 
para a outra, com exceção do mês de agosto, o qual apresentou temperaturas com mais de $5^{\circ} \mathrm{C}$ de diferença dos demais meses, como mostra a Figura 6.

O ponto dois, referente ao rio Itapetininga, apresentou maiores temperaturas em três das quatro análises, possivelmente devido a menor proteção em suas margens que faz com que a incidência solar seja maior, tenha um maior aporte de sedimentos com a erosão hídrica, além da região possuir indústrias que podem descartar águas com temperaturas mais elevadas.

A resolução CONAMA estabelece que o $\mathrm{pH}$ de água doce seja entre 6,0 e 9,0 (CONAMA, 2005). Com os valores representados na Figura 6 pode-se verificar que no verão e nas meias estações esse permaneceu dentro do estabelecido. Porém em agosto observou-se uma redução em todos os pontos, resultando em valores inferiores ao mínimo disposto na resolução.

Comparando o $\mathrm{pH}$ entre os diferentes pontos analisados, verificou-se que a maior diferença entre os valores obtidos foi de 0,31 . Apesar da pequena variação, o ponto um apresentou menores valores, enquanto no ponto três os mais elevados. Quanto mais próximo à neutralidade ( $\mathrm{pH}$ próximo a 7 ), maior a presença de sais, característico de locais mais poluídos. A mudança no $\mathrm{pH}$ da água, mesmo que com pouca variação, pode alterar o comportamento e sobrevivência de espécies no ecossistema que estão inseridos (WOLFF;DONATTI, 2016).

A redução do $\mathrm{pH}$ no inverno pode representar maior concentração de matéria orgânica na água, pois na decomposição dos mesmos ocorre a formação de ácidos, diminuindo o valor de $\mathrm{pH}$ (FUNASA, 2014). Tal situação pode também estar relacionada ao oxigênio dissolvido (OD), com menores concentrações em julho, ou seja, pode ocorrer maior consumo de oxigênio devido à maior concentração de matéria orgânica.

Um dos fatores que influenciam na presença do oxigênio na água é a temperatura, uma vez que os gases se tornam mais solúveis com a redução de temperatura (AMARAL et al., 2019). Notou-se que os meses mais quentes apresentaram menores concentrações de oxigênio dissolvido. Por sua vez, os meses mais frios apresentaram maiores concentrações. Porém, este é um parâmetro que está associado a diversos processos físicos, químicos e biológicos e varia por diferentes razões, portanto podem ocorrer variações em questão de um dia (FUNASA, 2014).

Nos períodos mais chuvosos a concentração de OD apresentou-se abaixo da resolução, que estabelece um mínimo de $5 \mathrm{mg} / \mathrm{L}$ para classe $\|$ e $6 \mathrm{mg} / \mathrm{L}$ para a classe I. Valores inferiores a $4,0 \mathrm{mg} / \mathrm{L}$, como apresentado nesses meses, caracterizam o rio como classe IV afetando a vida das espécies aquáticas. Segundo Funasa (2014) as atividades biológicas, especialmente devido a degradação da matéria orgânica, podem resultar em baixas concentrações de OD. Vale ressaltar que, mesmo fazendo o procedimento padrão de calibração, pode ter ocorrido anormalidade nos valores obtidos, uma vez que a membrana inserida no sensor é muito sensível, além de interferências por presença de impurezas (AMARAL et al., 2019).

Segundo Hanna (2018), para o parâmetro turbidez as unidades UNT e FNU são equivalentes, variando apenas os padrões de medição. A resolução estabelece que para corpos hídricos de classe I a turbidez deve ser inferior a 40 UNT. Na Figura 6 observa-se que três dos quatro pontos apresentaram valores inferiores ao estabelecido pela resolução. Esse limite é ultrapassado apenas no mês de abril. Os maiores valores nesse mês têm relação com as épocas de chuva e fortes ventos 
que levam sedimentos para os corpos hídricos e ficam em suspensão, afetando a turbidez da água.

Quando relacionado com a classe II todos os períodos e pontos deste parâmetro permaneceram inferiores ao determinado pela resolução (100 UNT). O ponto dois destacou-se por apresentar turbidez maior que nos outros pontos, com exceção do mês de outubro, isso pode se justificar devido à presença considerável de APPDs ao longo do rio Itapetininga.

Os sólidos totais dissolvidos, no geral, apresentaram valores muito próximos para todos os meses e pontos. Todos estão consideravelmente abaixo do valor de $500 \mathrm{mg} / \mathrm{L}$ estabelecido pela resolução. No ponto dois verificou-se valores mais altos em todas as análises, de $42 \mathrm{mg} / \mathrm{L}$, já o ponto 1 apresentou valores menores ou igual aos pontos 3 e 4 (27 mg/L).

O mesmo aconteceu para a condutividade elétrica, parâmetro relacionado a concentração iônica de espécies, em geral, inorgânicas. O ponto presente no rio Itapetininga apresentou valores maiores quando comparados aos outros pontos, enquanto o ponto um apresentou os menores valores. A água é capaz de transmitir corrente elétrica, devido aos sólidos dissolvidos totais presentes nela, portanto, é um indicador de salinidade que auxilia na avaliação da qualidade de corpos hídricos (FUNASA, 2014). Esses sais, podem estar relacionados à composição do solo da região, como também a presença de produtos dos setores agrícolas, industriais e domésticos (SILVA et al., 2017).

\section{CONCLUSÕES}

Com auxílio da técnica de geoprocessamento, pode-se concluir que a bacia do rio Itapetininga apresenta maiores ocorrências de áreas degradadas em comparação ao do rio Paranapanema. O passivo ambiental nas áreas de preservação permanente do Paranapanema é de $27,73 \%$ e a do Itapetininga de $44,89 \%$.

Verificou-se que o oxigênio dissolvido, turbidez e temperatura apresentaram expressiva variação dos valores entre as datas analisadas (estações do ano). Por outro lado, apresentou pouca variação entre os pontos analisados na mesma data de coleta. As concentrações dos parâmetros turbidez, sólidos totais dissolvidos e condutividade elétrica são maiores no rio Itapetininga. Tal fato pode estar relacionado ao maior percentual de áreas de preservação permanente degradadas nas margens deste rio.

\section{REFERÊNCIAS}

AMARAL, W. J.; SILVA, D. G.; ROSSONI, H. A. V.; SOUSA, G. V.; CAMPOS, A. C. V. Monitoramento da água do ribeirão Camarão/Lajes no município de Florestal, Minas Gerais. Revista Ponto de Vista, v. 1, n. 8, p. 88-97, 2019. ISSN: 19832656. Disponível em: https://periodicos.ufv.br/RPV/article/view/9206/3702. Acesso em: $04 / 05 / 2020$

AMÉRICO-PINHEIRO, J. H. P.; MIRANTE, M. H. P., BENINI, S. M. Gestão e qualidade dos recursos hídricos. Conceitos e experiências em bacias hidrográficas. Tupã: ANAP, $1^{\underline{a}}$ edição, 2016. ISBN: 978856824223 0. Disponível em: https://www.researchgate.net/profile/Sandra_Medina_Benini3/publication/311100097 Gestao_e_Qualidade_dos_Recursos_Hidricos_Conceitos_e_Experiencias_em_Bac ias_Hidrograficas/links/583d79b008aeda696806d850.pdf\#page $=21$. Acesso em: $20 / 12 / 2019$ 
ANA - Agencia Nacional de Águas (BRASIL). Conjuntura dos recursos hídricos no Brasil 2019: informe anual. Brasília, 2019. Disponível em: http://conjuntura.ana.gov.br/static/media/conjuntura-completo.bb39ac07.pdf. Acesso em: $10 / 04 / 2020$

BRASIL (2020a). Lei Federal no 12.651, 25 de maio de 2012. Dispõe sobre o Código Florestal. Diário Oficial (da) República Federativa do Brasil. Poder Executivo. Brasília, DF, 2012. Disponível em: http://www.planalto.gov.br/ccivil_03/_ato20112014/2012/lei/l12651.htm. Acesso em: 10/04/2020.

BRASIL (2020b). Lei Federal no 9.433, 08 de janeiro de 1997. Dispõe sobre a Política Nacional de Recursos Hídricos. Poder Executivo. Brasília, DF, 1997. Disponível em: <http://www.planalto.gov.br/ccivil_03/leis/19433.htm >. Acesso em: $13 / 04 / 2019$

BRASIL. Ministério do Meio Ambiente. Mata Atlântica: patrimônio nacional dos brasileiros. Brasília, DF: p. 41, 2010. ISBN 978-85-7738-133-3. Disponível em: https://ivroaberto.ibict.br/bitstream/1/984/2/Mata\%20atl\%C3\%A2ntica\%20patrimonio \%20nacional\%20dos\%20brasileiros.pdf. Acesso em: 19/04/2019

CBH-ALPA - Comitê da Bacia Hidrográfica do Alto Paranapanema. Plano da Bacia Hidrográfica do Alto Paranapanema (UGRHI 14) 2016-2027. Relatório I Informações Básicas, $2016 . \quad$ Disponível em: http://www.sigrh.sp.gov.br/public/uploads/documents//CBH-

ALPA/12024/relatorioalparevisaodezembrov5.pdf. Acesso em: 20/12/2019

CONAMA - Conselho Nacional Do Meio Ambiente. Resolução no 357, de 17 de março de 2005. Dispõe sobre a classificação dos corpos de água e diretrizes ambientais para o seu enquadramento, bem como estabelece as condições e padrões de lançamento de efluentes, e dá outras providências. Diário Oficial da União, n. 53, 18 mar. 2005, p. 58-63.

FUNASA - Fundação Nacional de Saúde. Manual de controle da qualidade da água para técnicos que trabalham em ETAS. Ministério da Saúde, BRASIL Brasília: $\quad$ Funasa, $2014 . \quad$ Disponível em: http://www.funasa.gov.br/documents/20182/38937/Manual+de+controle+da+qualidad e+da+\%C3\%A1gua+para+t\%C3\%A9cnicos+que+trabalham+em+ETAS+2014.pdf/85 bbdcbc-8cd2-4157-940b-90b5c5bcfc87. Acesso em: 04/05/2020

GOMES, C. S. Impactos da expansão do agronegócio brasileiro na conservação dos recursos naturais. Cadernos do Leste, vol. 19, n. 19, p. 63-78, 2019. ISSN: 1679 5806. https://periodicos.ufmg.br/index.php/caderleste/article/view/13160/10396. Acesso em: 10/04/2019.

GUEDES, J. C. F.; SILVA, S. M. P. Sensoriamento remoto no estudo da vegetação: princípios físicos, sensores e métodos. ACTA Geográfica, v.12, n.29, p. 127-144, 2018. ISSN: $2177 \quad 4307 . \quad$ Disponível em: https://revista.ufr..br/actageo/article/view/4001/2522.

DOI: http://dx.doi.org/10.5654/acta.v12i29.4001 
HANNA Instruments Brasil. O Guia Completo para Medição de Turbidez na Água. Abril, 2018. Disponível em: https://hannainst.com.br/dicas-dos-especialistas/o-guiacompleto-para-medicao-de-turbidez-na-agua/. Acesso em: 06/05/2020

IBGE- Instituto Brasileiro de Geografia e Estatística. Altera a caracterização do Sistema Geodésico Brasileiro. Resolução do presidente. 25 de fevereiro de 2005. Disponível em: http://geoftp.ibge.gov.br/metodos_e_outros_documentos_de_referencia/normas/rpr_ 01_25fev2005.pdf. Acesso em: 20/12/2019

MAPBIOMAS - Mapeamento Anual da Cobertura e Uso do Solo do Brasil. 2019. Disponível em: <http://mapbiomas.org>. Acesso em: 19/04/2019.

National Aeronautics and Space Administration (NASA). Landsat - SRTM Shaded Relief Comparison, Los Angeles and Vicinity. 7 de novembro de 2002. Disponível em: <https://www.jpl.nasa.gov/spaceimages/details.php?id=PIA03373>. Acesso em: $18 / 12 / 2019$

REZENDE, G. B. M.; ARAÚJO, S. M. S. As cidades e as águas: ocupações urbanas nas margens de rios. Revista de Geografia (Recife), v. 33, n. 2, p. 119-135, 2016. ISSN $0104 \quad 5490 . \quad$ Disponível em: https://periodicos.ufpe.br/revistas/revistageografia/article/viewFile/229173/23572.

Acesso em: 10/04/2019

SÃO PAULO (Estado) - Secretaria do Meio Ambiente. Meio ambiente paulista: relatório de qualidade ambiental 2018. São Paulo, p. 56-57. 2018. Disponível em: http://s.ambiente.sp.gov.br/cpla/RQA_2018.pdf. Acesso em: 19/04/2019

SIGRH - Sistema Integrado de Gerenciamento de Recursos Hídricos do Estado de São Paulo (2019a). Caracterização Geral da UGRHI 14. s/d. Disponível em: http://www.sigrh.sp.gov.br/public/uploads/documents/6997/CARACTERIZACAO_GE RAL_DA_UGRHI_14.html. Acesso em: 20/12/2019

SIGRH - Sistema Integrado de Gerenciamento de Recursos Hídricos do Estado de São Paulo (2019b). Histórico do Desenvolvimento da Região. s/d. Disponível em: http://www.sigrh.sp.gov.br/public/uploads/documents/6723/131_alpa.htm. Acesso em: 20/12/2019

SILVA, M. A.; VARGAS, R. R.; SAAD, A. R.; ROSSINI, E. F.; QUEIROZ, W. Reflexos do uso da terra na qualidade da água da bacia hidrográfica do córrego taboão, Guarulhos (SP). Revista UNG - Geociências, v. 16, n.1, p. 69-86, 2017. ISSN: 1981 741X. Disponível em: http://revistas.ung.br/index.php/geociencias/article/view/2952/2151. Acesso em: $13 / 04 / 2019$

WOLFF, L. L.; DONATTI, L. Estudo do comportamento do peixe de água doce Pphalloceros harpagos (Cyprinodontiformes: Poeciliidae) submetido à alteração artificial do pH. Luminária, União da Vitória, v.18, n. 1, p. 10-21, 2016. ISSN: 2359 $4373 . \quad$ Disponível em: http://periodicos.unespar.edu.br/index.php/luminaria/article/view/1026/587. Acesso em: 04/05/2020 